\title{
LA ESCUELA EN LA CONSTRUCCIÓN \\ DE LAS FRONTERAS CULTURALES Y LINGÜÍSTICAS \\ EN EL URUGUAY DE FINES DEL SIGLO XIX
}

\section{The school in construction of cultural and linguistic borders in Uruguay of the end of the Nineteenth Century}

\author{
MARIELA OROÑO*
}

Recibido: 10-04-2016

Revisado: 04-05-2016

Aceptado: 05-05-2016

RESUMEN. A fines del siglo XIX, Uruguay inició su primer período de construcción nacional. La reforma escolar de 1877, liderada por José Pedro Varela, desempeñó un rol fundamental en este proceso. En este trabajo se estudia como la escuela construyó las fronteras culturales y lingüísticas del país, mediante la creación de escuelas rurales y la preocupación por el uso del portugués en las escuelas rurales fronterizas, representándolo como amenaza a la nacionalidad. Se analizan obras pedagógicas e informes técnicos de Varela y otros documentos de la reforma. Primero se presenta el contexto socio- histórico y educativo del país y la figura de Varela. Luego se discute el lugar asignado a la lengua y a la escuela, y en particular a las escuelas rurales.

\footnotetext{
* Doctoranda en Lingüística, magíster en Ciencias Humanas, opción Lenguaje Cultura y Sociedad, licenciada en Lingüística por la Udelar (Universidad de la República Oriental del Uruguay), y profesora de Idioma Español en la Administración Nacional de Educación Pública (Uruguay). Docente del Instituto de Lingüística de la Facultad de Humanidades y Ciencias de la Educación de la Udelar e integrante del Sistema Nacional de Investigadores de la Agencia Nacional de Investigación e Innovación (ANII). Investiga aspectos sobre políticas e ideologías lingüísticas en relación con la construcción de la identidad nacional.
} 
La escuela en la construcción de las fronteras culturales y lingüísticas en el Uruguay de fines del siglo XIX

Palabras clave: Uruguay, siglo XIX, fronteras nacionales, escuela, lenguaje

\begin{abstract}
At the end of the nineteenth century, Uruguay began its first period of national construction. School reform of 1877 led by Jose Pedro Varela played a key role in this process. In this paper I study how the school built the cultural and linguistic borders by creating rural schools and the preoccupation for the use of Portuguese in border rural schools, representing it as a threat to nationality. I analyze of pedagogical works and written reports by Varela being National Inspector of Education and other documents of the school reform. First I present the historical and socio- educational context of the country and the figure of Varela. Then I discuss the place assigned to the language and the school, particularly to rural schools.
\end{abstract}

Keywords: Uruguay, Nineteenth Century, national boundaries, school, language

Revista Páginas de Educación. Vol. 9, Núm. 1 (2016) ISSN: 1688-5287; e-ISSN: 1688-7468 
La escuela en la construcción de las fronteras culturales y lingüísticas en el Uruguay de fines del siglo XIX

\section{INTRODUCCIÓN ${ }^{1}$}

Uruguay nació como Estado independiente en 1828 como consecuencia de intereses políticos ajenos, más que por una voluntad de independencia nacional de los propios orientales (Nahum, 1994; Caetano y Rilla, 1994). Estas circunstancias impiden hablar de la existencia en esa época de una nación claramente definida (Caetano, 1992); es decir, de "una comunidad política imaginada como políticamente limitada y como soberana" (Anderson, 1993, p. 23). Precisamente el centro de las preocupaciones de los intelectuales uruguayos del siglo XIX fue la viabilidad del Uruguay como Estado independiente y la construcción de una identidad nacional que cohesionara realidades demográficas, culturales y lingüísticas muy diferentes: grosso modo, el norte con una fuerte presencia lusitana y el sur con un predominio hispano más el agregado de grupos migratorios arribados en grandes oleadas desde mediados de siglo (Behares, 1984; Barrios, Behares, Elizaincín, Gabbiani, \& Mazzolini, 1993).

La demarcación de las fronteras políticas y lingüísticas y la homogeneización cultural y lingüística adquirieron un lugar especialmente importante durante el período de modernización ${ }^{2}$ (Behares, 2007) -iniciado con la dictadura del Coronel Lorenzo Latorre, (1876-1879)-, con especial atención al estatus del castellano en relación con el portugués (Barrios, 2013), debido a que el interés central del período fue ordenar la campaña y contrarrestar la presencia brasileña en el norte del país (Caetano y Rilla, 1994). Para lograr este objetivo las acciones apuntaron, entre otras cosas, a eliminar las diferencias lingüísticas mediante la difusión y consolidación del castellano como lengua nacional (Behares, 2007; Barrios, 2013; Oroño, 2013).

La aplicación del Decreto-ley de Educación Común nº 1350 de 1877 (Argone, 1987) fue un instrumento fundamental para lograr la creación de un sistema escolar

\footnotetext{
${ }^{1}$ Este estudio forma parte de mi investigación de doctorado en curso. Una versión muy preliminar de este trabajo fue aceptada para su publicación en las actas de un congreso.

${ }^{2}$ Se entiende por modernización el período 1877-1894 (aunque el proceso se inició antes y se continuó después), en el que Uruguay, "acompasó su evolución demográfica, tecnológica, económica, política, social y cultural a la Europa capitalista, entrando a formar parte de su círculo de influencia directa” (Barrán, 2008, p. 218).
}

Revista Páginas de Educación. Vol. 9, Núm. 1 (2016) ISSN: 1688-5287; e-ISSN: 1688-7468 
La escuela en la construcción de las fronteras culturales y lingüísticas en el Uruguay de fines del siglo XIX

estatal eficiente (Behares, 2007; Barrios, 2013; Oroño, 2011 y 2013). Se inició entonces la reforma escolar de 1877, que estableció la obligatoriedad de la enseñanza primaria e impuso el castellano como la lengua de instrucción pública, con lo cual el aparato estatal alcanzó una cobertura nacional (aunque con resultados distintos según la zona, cfr. Elizaincín, 1979; Behares, 1984; Barrios et al., 1993). José Pedro Varela (18451879; pedagogo, periodista, político y escritor) lideró la puesta en práctica de la reforma escolar desde su cargo de Inspector Nacional de Instrucción Pública. En tanto planificador de la educación escolar estatal y competente (Altamirano, 2008 ${ }^{3}$ ) al servicio de la construcción del Estado nacional, la cuestión de la lengua fue una de sus preocupaciones.

En este trabajo se analiza como la escuela construyó las fronteras culturales y lingüísticas del país a partir de la creación de escuelas rurales y de la preocupación por el uso del portugués en las escuelas rurales fronterizas, representándolo como amenaza a la nacionalidad. Para ello se estudian los textos pedagógicos de Varela ( $L a$ educación del pueblo, 1874; La legislación escolar, 1876) y la memoria escolar que da cuenta de su trabajo como Inspector Nacional de Instrucción Pública entre agosto de 1877 y 1878 (Memoria del Inspector Nacional. 1877-1878, 1879). También se analizan las actas de las Conferencias de Inspectores Departamentales de 1878. Tengo en cuenta además legislación educativa del período. Los procesos de producción, distribución y consumo de los documentos mencionados (Fairclough, 2001) indican su relevancia.

El libro La educación del pueblo fue el resultado de un proceso particular: la Sociedad de Amigos de la Educación Popular ${ }^{4}$ designó a Varela para redactar un informe que fundamentara y explicitara la organización y el plan curricular de la escuela

\footnotetext{
${ }^{3}$ Altamirano (2008) destaca el rol de los intelectuales en la construcción de los estados nacionales, señalando que la unificación del Estado (la consolidación del territorio, la redacción de leyes, el impulso a la educación pública) requirió "competentes que pudieran producir y ofrecer conocimientos, sean legales, geográficos, técnicos o estadísticos" y publicistas que "pudieran suministrar discursos de legitimación destinados a engendrar la alianza incondicional de los ciudadanos con 'su' Estado -narrativas de la patria, de la identidad nacional” (p. 10).

${ }^{4}$ Esta sociedad se fundó en 1868 a instancias de varios intelectuales jóvenes interesados en la educación, entre ellos José Pedro Varela, como se explica más adelante en este trabajo.
}

Revista Páginas de Educación. Vol. 9, Núm. 1 (2016) ISSN: 1688-5287; e-ISSN: 1688-7468 
La escuela en la construcción de las fronteras culturales y lingüísticas en el Uruguay de fines del siglo XIX

que deseaba fundar la Sociedad para presentarlo a interesados en brindar fondos para la construcción del edificio escolar. Varela escribió un texto más ambicioso que lo acordado; redactó un manual de pedagogía cuya publicación financió la Sociedad, por lo que pudo alcanzar una circulación mayor a la inicialmente prevista. El mismo año de su publicación (1874), el libro fue premiado con medalla de oro en la Exposición Internacional de Chile, por lo que el texto adquirió un prestigio que seguramente propició su consumo por los involucrados en temas educativos.

El segundo libro pedagógico de Varela, La legislación escolar, fue escrito ya contando él con reconocimiento público como pedagogo. En este texto, Varela fundamentó la importancia de la educación para la construcción del Estado nacional y presentó su modelo de sistema escolar estatal. El texto se divide en dos partes; la primera incluye reflexiones sociológicas sobre la realidad nacional. En la segunda estudia "Los fines y ventajas de aunar los esfuerzos del Estado y de las localidades para poder realizar la obra de la educación". La última sección contiene el "Proyecto de Ley de Educación Común" y sus fundamentos pedagógicos. Este proyecto es la base de la Ley de Educación Común $n^{\circ}$ 1350. Tanto La educación del pueblo como La legislación escolar tuvieron muchas reimpresiones y ediciones, lo que indica la importancia de su difusión y consumo.

La redacción de la memoria escolar respondió al cumplimiento de los artículos 25 y 26 del Decreto Ley de Educación Común, según los cuales el Inspector Nacional de Instrucción Pública debía enviar un informe anual a la Dirección General de Instrucción Pública sobre el estado de la educación escolar del país. El informe "después de discutido y aprobado por aquélla, será publicado en forma de libro y se le dará la circulación que juzgue conveniente la Dirección General" (art. 25, Decreto Ley de Educación Común $n^{0} 1350$ ). Este texto tuvo una primera difusión a la interna del sistema escolar y luego se publicó como libro, por única vez, alcanzado entonces una distribución pública, aunque probablemente de consumo limitado. Es un texto muy extenso. El informe del inspector tiene 126 páginas organizadas en 18 capítulos. La mayoría de ellos se estructuran del siguiente modo. Se inicia con la referencia a la Revista Páginas de Educación. Vol. 9, Núm. 1 (2016) ISSN: 1688-5287; e-ISSN: 1688-7468 
La escuela en la construcción de las fronteras culturales y lingüísticas en el Uruguay de fines del siglo XIX

aplicación de las disposiciones legales reguladoras del proceso instaurador de la reforma escolar y los criterios operativos adoptados por la Dirección General o el propio Inspector Nacional. Luego se describen las acciones realizadas, en particular aquellas que habían sido criticadas, que habían tenido dificultades para aplicarse o que consideraba equivocadas. Finalmente, Varela informaba de las medidas adoptadas o a adoptarse para superar los errores o dificultades, o respondía a las críticas realizadas. La memoria escolar incluye además 1050 páginas de anexos con los informes de los inspectores de los 13 departamentos del país y estados y cuadros estadísticos elaborados por Varela. Las actas de la Conferencias de los Inspectores Departamentales se transcriben precisamente en uno de esos anexos.

Las actas transcriben textualmente la discusión entre los asistentes a las primeras Conferencias de Inspectores Departamentales de Educación Primaria, realizadas entre el 6 y el 13 de agosto de 1878 en el departamento de Durazno. En las reuniones participaron el Inspector Nacional de Instrucción Primaria (José Pedro Varela), el vocal de la Dirección General (Juan Álvarez y Pérez) y los inspectores de escuela de los 13 departamentos existentes entonces en Uruguay ${ }^{5}$. Todas las sesiones trataron temas relativos a las escuelas rurales. El texto de las actas tuvo la misma circulación que el cuerpo de la memoria escolar, aunque seguramente haya sido menos leído que el informe del inspector nacional debido a su disposición marginal en tanto anexo de la memoria.

\section{JOSÉ PEDRO VARELA Y LA REFORMA ESCOLAR DE 1877}

Como se ha señalado, José Pedro Varela ocupó un lugar fundamental en la estructuración del sistema escolar estatal y en la difusión del castellano como idioma

\footnotetext{
${ }^{5}$ Juan M. de Vedia y Julián O. Miranda (de Montevideo), Julián Becerro de Bengoa (de San José, que incluía el actual departamento de Flores), Germán Fassauer (de Salto, formado también por el actual departamento de Artigas), Federico F. Calvet (de Minas, actual Lavalleja), Erasmo Bogorja de Skotnicki (de Cerro Largo, que incluía lo que hoy es Treinta y Tres), Juan Martínez Ruiz (de Florida), Andrés Dubra y Seoane (de Canelones), Ramón López Lomba (de Paysandú, que incluía Río Negro), Eugenio Luis Zorrilla (de Maldonado, formado también por Rocha), Juan Pérez (de Soriano), Jaime Ferrer y Barceló (de Durazno), Francisco Morelli (de Colonia) y Valentín Astor (de Tacuarembó, que incluía Rivera) (Varela, 2012 [1879]).

Revista Páginas de Educación. Vol. 9, Núm. 1 (2016) ISSN: 1688-5287; e-ISSN: 1688-7468
} 
La escuela en la construcción de las fronteras culturales y lingüísticas en el Uruguay de fines del siglo XIX

nacional, instrumentos centrales para la unificación cultural y lingüística del Uruguay (Behares, 1984; Barrios, 2013; Oroño, 2011 y 2013). Su preocupación era transformarlo en un Estado nacional y moderno, y para ello ubicó a la educación y al castellano (lengua nacional) como centro de la cuestión.

Integrante de una importante familia de comerciantes con "singular selección de valores sociales, morales e intelectuales" (Bralich, 1989, p. 9), Varela (que, a diferencia de la mayoría de la élite de la época, no tenía formación universitaria) comenzó a participar en la vida intelectual del país desde muy joven, publicando artículos en diversos periódicos. En estos textos ya manifestaba su anticlericalismo y su creencia en el valor de la educación para crear un Estado moderno (Ardao, 1971; Bralich, 1989). Para lograr este objetivo su referente era Estados Unidos, aun antes del significativo viaje que realizó a este país en 1868 (en el que conoció al político y escritor argentino Domingo Faustino Sarmiento, y a partir del cual difundió en Uruguay las nuevas corrientes sociales y pedagógicas sajonas; cfr. Ardao, 1971; Araújo, 1911).

Sus intereses educativos lo llevaron a fundar en 1868, junto con otros intelectuales de la época, la Sociedad de Amigos de la Educación Popular, de la que fue su presidente entre 1869 y 1876. En el discurso que brindó con motivo de su fundación, posicionándolo como un referente de la educación popular (Bralich, 1989; Palomeque, 2012), Varela destacó el papel de la educación en la construcción del Estado y del ciudadano: "la escuela es la base de la República"; fomenta la obediencia y la homogeneidad social, porque "En ella hay un orden fijo, una regla establecida que el niño aprende a respetar" y "Esto hace que el adulto respete la ley y reconozca la autoridad", y porque "aproxima y funde las clases sociales" (Sociedad de Amigos de la Educación Popular, 1869, 3). Varela explicitó aún más el vínculo entre escuela y ciudadanía: "Para establecer la República, lo primero es formar los republicanos. (...) la educación [es] la condición indispensable de la ciudadanía" (1910 [1874], p. 56).

En febrero de 1876, Varela fue designado presidente de la Comisión de Instrucción Pública de la Junta Económico Administrativa de Montevideo, que por 
La escuela en la construcción de las fronteras culturales y lingüísticas en el Uruguay de fines del siglo XIX

decreto de Latorre tenía jurisdicción nacional. Varela aceptó el cargo propuesto por el dictador, aunque manifestando:

Volviendo en nombre de elevadas consideraciones de patriotismo sobre una primera resolución, tomada ya, e imponiéndome al hacerlo, el arduo sacrificio de legítimos escrúpulos y de fundadas resistencias, acepto el puesto para el cual se me nombra, con el firme y decidido propósito de servirle fielmente en la medida de mis facultades, mientras crea poder hacerlo en pro de los intereses públicos y sin mengua de la dignidad del ciudadano y del hombre. (carta a Latorre de fecha 27 de marzo de 1876. Ardao, 1971, p. 122)

Entonces Varela elevó al Ministro de Gobierno su proyecto de ley de educación contenido en La Legislación escolar (1964 [1876]) para que el Gobierno Provisorio, "haciendo uso de sus facultades ordinarias y extraordinarias", lo convirtiera en ley, "con evidente conveniencia para los intereses permanentes de la República, sea aceptándolo tal como ha sido formulado, o introduciendo en él las modificaciones que juzgare necesarias" (p. 7).

El 24 de agosto de 1877 el gobierno aprobó el proyecto de Varela, con modificaciones. Varela proponía descentralizar la organización educativa existente, en un marco de gratuidad, obligatoriedad y laicidad. El Decreto-ley de Educación Común no 1350, firmado por Latorre, definió un sistema educativo con estructura centralizada y con educación religiosa (aunque no obligatoria). Varela fue nombrado Inspector Nacional de Instrucción Pública (cargo que desempeñó hasta su muerte en 1879) y comenzó lo que se conoce como reforma escolar vareliana. Aunque liderada por Varela, fue un proceso colectivo en el que intervinieron figuras relevantes del ámbito intelectual nacional vinculadas con la Sociedad de Amigos de la Educación Popular, cuya escuela insignia (el colegio Elbio Fernández) ensayó la estructura curricular y las propuestas pedagógicas extendidas luego a todas la escuelas nacionales (Mena Segarra y Palomeque, 2011).

La aplicación del Decreto-Ley de Educación Común implicó la unidad y control de la educación primaria por un único ente (la Dirección General de Instrucción Pública), la existencia de una autoridad nacional (el Inspector Nacional), que contaba con órganos Revista Páginas de Educación. Vol. 9, Núm. 1 (2016) ISSN: 1688-5287; e-ISSN: 1688-7468 
La escuela en la construcción de las fronteras culturales y lingüísticas en el Uruguay de fines del siglo XIX

subordinados en cada departamento, y la fiscalización de los departamentos por funcionarios especializados (los inspectores) (art. 34). También se le asignaron a la Dirección General de Instrucción Pública potestades de resolución sin que el Poder Ejecutivo pudiera revisar sus decisiones. Aunque también es cierto que sus miembros (el Ministro de Gobierno, el Inspector Nacional, el Director de la Escuela Normal y cuatro vocales) debían ser elegidos por el Gobierno (art. 2) y durar en sus funciones hasta que "su comportación no dé motivo para ser removidos de sus puestos" (art. 4). En resumen, el sistema escolar estatal creado era una organización piramidal y jerarquizada en cuyo vértice se ubicaba la Dirección General de Instrucción Pública, dependiente del poder político. Ésta se encargaba de transmitir a los inspectores y directores de escuela las disposiciones que los maestros debían cumplir y hacer cumplir. La Dirección General tenía autonomía técnica y administrativa, aunque siempre dentro de los límites impuestos por su dependencia política y financiera.

La aplicación del Decreto-ley de Educación Común también significó la confirmación de la gratuidad de la enseñanza (art. 13; existente desde 1827), hecho que adquirió gran relevancia gracias a su simultánea obligatoriedad (arts. 15, 20, 21 y 22). Estas características permitieron que el sistema escolar tuviera un verdadero alcance nacional; la escuela llegaba a los parajes más alejados del medio rural, incluso a donde la Iglesia no lo hacía. En cuanto a la laicidad, el artículo 18 del decreto-ley estableció que "la enseñanza de la Religión Católica [sería] obligatoria en las escuelas del Estado, exceptuándose a los alumnos que profesen otras religiones y cuyos padres y tutores o encargados se opongan a que la reciban"6.

\footnotetext{
${ }^{6}$ Varela no ocultó su desacuerdo con este punto; en una carta publicada en El Bien Público el 18 de enero de 1879 expresaba: "La comisión nombrada por el Gobierno introdujo grandes modificaciones en mi proyecto y una de ellas fue el art. 18 que no es obra mía y que he considerado siempre inconveniente" (Mena Segarra y Palomeque, 2011, p. 424). En La Legislación escolar (1964 [1876], p. 261) ya reconocía: "Ahora bien: aún cuando nosotros creamos que es mejor la escuela pública en que no se enseña religión positiva alguna, creemos también que entre la escuela con catecismo y la carencia de escuela, es mejor lo primero que lo último". Esta concesión se debe a que la Constitución vigente establecía que la religión del Estado uruguayo era la Católica Apostólica Romana. La religión fue desligada de la educación en 1909, cuando se aprobó (el 6 de abril) la ley no 3409 que suprimió "toda enseñanza y práctica religiosa en las escuelas del Estado" (Araújo, 1911); hecho ratificado en la Constitución de 1917, que estableció la separación entre la Iglesia y el Estado.

Revista Páginas de Educación. Vol. 9, Núm. 1 (2016) ISSN: 1688-5287; e-ISSN: 1688-7468
} 
La escuela en la construcción de las fronteras culturales y lingüísticas en el Uruguay de fines del siglo XIX

La lengua fue un aspecto central de la reforma educativa: el artículo 38 del Decreto-Ley de Educación Común estableció que "En todas las escuelas públicas, la enseñanza se dará en el idioma nacional" (Araújo, 1898), asumiéndose que éste era el castellano. A partir de entonces el castellano se formalizó como la lengua de instrucción; la lengua en la que se debían dictar las clases y escribir los libros de texto.

Tanto en el proyecto vareliano de reforma educativa, como en el decreto-ley efectivamente aprobado, el artículo 38 citado es la única mención explícita a cuestiones vinculadas con la lengua. Sin embargo, su contenido es muy significativo, porque los diseños curriculares escolares han seguido esta prescripción (Behares y Brovetto, 2009). Se estableció que los contenidos programáticos de la escuela pública se enseñaran obligatoriamente en castellano. Por otra parte, en la asignatura "Idioma nacional" de los programas escolares del período (que nucleaba el estudio del "Lenguaje", la "Escritura" y la "Lectura") se enseñaba la gramática, la escritura y la lectura del castellano (Oroño, 2013).

\section{LA ESCUELA Y LA DELIMITACIÓN DE LAS FRONTERAS ESTATALES. LA CUESTIÓN DEL PORTUGUÉS}

En el último cuarto del siglo XIX el tema de la lengua aparece estrechamente vinculado con la consolidación de las fronteras políticas y culturales, para salvaguardar la existencia del Estado uruguayo. Como señala Varela en La Legislación escolar: "Los peligros inmediatos, que pesan exclusivamente sobre nosotros como pueblo independiente, se refieren a la nacionalidad" (1964 [1876], p. 147). Los peligros en cuestión eran la población extranjera y la demarcación de fronteras con Brasil, incluyendo el uso del portugués:

En la hora actual, el Brasil, después de continuados y pacientes esfuerzos, domina con sus súbditos, que son propietarios del suelo, casi todo el Norte de la República: en toda esa zona, hasta el idioma nacional casi se ha

Revista Páginas de Educación. Vol. 9, Núm. 1 (2016) ISSN: 1688-5287; e-ISSN: 1688-7468 
La escuela en la construcción de las fronteras culturales y lingüísticas en el Uruguay de fines del siglo XIX

perdido $\mathrm{ya}^{7}$, puesto que es el portugués el que se habla con más generalidad. (op. cit. p. 149)

No hay que olvidar tampoco que una tercera parte, a lo menos, de nuestra población es extranjera; extraña en consecuencia a la nacionalidad, y que sólo aspira a gozar de tranquilidad y garantías bastantes para que su industria y su trabajo puedan ejercitarse libremente. (op. cit. p. 150)

La población extranjera, que fue aumentando significativamente a lo largo del siglo XIX, implicaba una situación de multilingüismo y contacto entre lenguas muy acentuada. Se esperaba entonces que la escuela cumpliera "Activa y poderosamente a salvar nuestro idioma, nuestras costumbres buenas, y aún nuestra raza de una ruina inevitable" (Varela, 1964 [1876], p. 170). La lengua, las costumbres y la raza se destacaron como atributos de la nacionalidad uruguaya y establecieron una oposición entre "nosotros" ("nuestro idioma", "nuestras costumbres", "nuestra raza") y "los otros" (representados por los inmigrantes y brasileños). Se representa a estos grupos como los responsables de ocasionar la fragmentación nacional, con lo que se evidencia el papel de las representaciones en la creación de la realidad social (Moscovici, 1993; Jodelet, 1993), ya que la identidad nacional estaba recién construyéndose. La creación de una conciencia nacional (Anderson, 1993) implicaba la demarcación de las fronteras políticas, pero también identitarias (Barth, 1976).

Un año más tarde, desde su rol de planificador de la educación escolar estatal en tanto Inspector Nacional de Instrucción Pública, vuelve a manifestar esta preocupación. En su segunda (y última) memoria escolar (Varela, 2012 [1879], p. 124) señalaba: "El idioma es el más poderoso vínculo de la nacionalidad; es por medio de él que se unifican las ideas, las aspiraciones y los sentimientos de las nacionalidades, en tanto que la diferencia de idioma entre los súbditos levanta una barrera casi insalvable para la constitución permanente de los Estados".

\footnotetext{
7 En esta cita, como ha señalado Barrios (2013), “we can find the distortion - "erreur historique," in Renan's (1987 [1882]) terms - of considering the situation along the border as the result of a displacement of Spanish by Portuguese ("the national language has almost been lost"), when in fact, since the first settlements in the region, the dominant language had been Portuguese" (p. 200).
}

Revista Páginas de Educación. Vol. 9, Núm. 1 (2016) ISSN: 1688-5287; e-ISSN: 1688-7468 
La escuela en la construcción de las fronteras culturales y lingüísticas en el Uruguay de fines del siglo XIX

El portugués en particular recibió especial atención, pues lo interpretaba como una amenaza a la nacionalidad (Barrios, 2013; Oroño, 2013): "La República Oriental tiene una gran amenaza y un gran peligro para el porvenir, en lo difundido que se hallaba el idioma brasilero en los Departamentos que son limítrofes del Imperio" (Varela, 2012[1879], p. 124).

A pesar de que un cuarto de la población de Uruguay era de origen europeo (Vidart y $\mathrm{Pi}, 1969$ ), la principal preocupación en este momento histórico era la delimitación de fronteras en el norte del joven país. Se trataba de un problema político y económico importante que se reflejó en las representaciones y políticas lingüísticas de la época ${ }^{8}$. La población inmigrante, aunque numéricamente muy significativa, era más accesible al control estatal y estaba interesada en aprender el castellano para facilitar su inserción social y laboral (incluso las instituciones educativas étnicas se crearon como bilingües y enseñaron el castellano a los hijos de estos inmigrantes, cfr. Barrios, 2013). El hecho de que los mismos encargados de llevar adelante la reforma escolar fueran en su mayoría inmigrantes europeos, muestra su compenetración con el país de residencia. Los colaboradores de Varela eran casi exclusivamente inmigrantes, al igual que diez de los 13 Inspectores Departamentales designados por éste en $1877^{9}$.

La amenaza del portugués era económica y política, además de cultural y lingüística. Los propietarios de gran parte de las tierras del norte del país eran brasileños y mantenían su lengua y costumbres (Elizaincín, Behares, Barrios, 1987; Barrios, 2013), lo que obligaba a que incluso la administración pública vinculada con la actividad de jueces y policías se realizara en portugués. Este último aspecto ha sido documentado por Coll (2009).

No es sólo que esa importante zona de la República, una gran parte del suelo sea propiedad de ciudadanos brasileros; no es sólo que éstos se encuentren allí

\footnotetext{
${ }^{8}$ Sobre el "problema del portugués" en éste y otros momentos históricos del país, cfr. Elizaincín, 1979; Behares, 1984, Barrios, 2013, 2015 y en prensa.

${ }^{9}$ Entre ellos, Francisco Antonio Berra, Emilio Romero y Alfredo Vásquez Acevedo, que eran argentinos, y Carlos María Ramírez, que era brasileño. En cuanto a los inspectores departamentales, seis eran españoles, tres eran italianos, uno era alemán y otro polaco (Mena Segarra y Palomeque, 2011).
}

Revista Páginas de Educación. Vol. 9, Núm. 1 (2016) ISSN: 1688-5287; e-ISSN: 1688-7468 
La escuela en la construcción de las fronteras culturales y lingüísticas en el Uruguay de fines del siglo XIX

en gran número; es que por la natural influencia que ejercen en su riqueza y por el amor que profesan naturalmente al idioma nativo, los hijos de brasileros que nacen en la República sólo hablan el idioma de sus padres, y comparten con ellos las ideas, las aspiraciones y los sentimientos. (...) Hay más todavía, la misma población de origen nacional que vive en esos Departamentos se ve casi obligada, en sus transacciones, en sus trabajos, en su quehaceres diarios a valerse, no del idioma nacional, sino del brasilero; llega a menudo el caso de que las autoridades subalternas, Jueces de Paz, Comisarios de Policía, Celadores, etc., hablen y escriban, cuando saben hacerlo, en brasilero. Los sumarios que levantan los Jueces de Paz de Salto, Tacuarembó, Cerro Largo, Maldonado y Paysandú, y que remiten a Montevideo, suelen venir en brasilero; a los testigos se les interroga en brasilero y en ese idioma contestan; las actas se labran también en brasilero, y, en una palabra, puede decirse sin exageración alguna, que el idioma predominante en gran escala en esa vasta sección de la República no es el nacional (Varela, 2012 [1879]: pp. 124 y 125).

Como señalaba Varela, en la región limítrofe con Brasil habitaban "brasileros nacidos en la República", por lo que era de esperar que no tuvieran

vínculo alguno que lo ligue a nuestro país, que los haga verdaderamente nuestros compatriotas; son brasileros nacidos en la República; y tan es así, que si preguntáis a la gran mayoría de los hijos de brasileros que vive en los Departamentos del Norte, cuál es su nacionalidad, contestan que "son brasileros" y no ocultan, sin embargo, que han nacido en tal o cual punto de la República (op. cit., p. 124).

Los datos demográficos del período respaldan esta observación. El censo de 1860 indica que en Uruguay habitaban unas 200.000 personas, de las cuales 40.000 eran brasileños y vivían en el norte del país (Barrios, 2013).

Esta situación obligaba a desarrollar políticas de nacionalización de esa población, entre las que ocupaba un lugar destacado la imposición del "idioma nacional" a todos los habitantes del país. El Estado tenía "el derecho para imponer a los padres la obligación de enseñar a sus hijos el idioma nacional” (Varela, 2012 [1879], p. 125) porque su conocimiento era fundamental para que los sujetos cumplieran los deberes Revista Páginas de Educación. Vol. 9, Núm. 1 (2016) ISSN: 1688-5287; e-ISSN: 1688-7468 
La escuela en la construcción de las fronteras culturales y lingüísticas en el Uruguay de fines del siglo XIX

que la ciudadanía imponía: ser jurado, servir en la guardia nacional, conocer y cumplir las leyes.

La Constitución de la República establece que la ley no exime de responsabilidad en los casos en que a ella se falte; y para que esto no sea monstruoso, es necesario admitir que se parte del supuesto que todos los ciudadanos están en aptitud de conocer lo que la ley manda; pero ¿cómo puede hacerse una suposición semejante cuando se trata de ciudadanos que no conocen el idioma (...)? Además, la ciudadanía impone cargas que no son renunciables: todo ciudadano tiene que servir en la guardia nacional, que ser jurado, etc. Ahora bien, ¿puede ser jurado el que no conoce el idioma patrio? $Y$ el Estado, ¿no tiene derecho a exigir a todos los ciudadanos que, al menos, no se priven voluntaria y deliberadamente, de aquellas condiciones que son indispensables para el ejercicio de la ciudadanía y sobre todo para el cumplimiento de los deberes que ella impone? (Varela, op. cit., p. 125).

El conocimiento del idioma nacional era el mejor medio para transformar a los habitantes del país en ciudadanos uruguayos. Por el contrario, "no enseñar el idioma patrio a los que nacen en la República, es ir destruyendo paulatina pero constantemente la independencia de la nación y a la vez, si no es conspirar contra la Constitución, es hacer imposible su cumplimiento" (op. cit., p. 125). El modo de que todos los individuos aprendieran castellano era que "el idioma nacional se enseñe en todas las escuelas del Estado, sean públicas o particulares" (op. cit., p. 125).

La escuela y la enseñanza del castellano como idioma nacional se reconocieron como elementos fundamentales para construir la nación. La alfabetización en castellano garantizaría la civilización y la nacionalización de la población al inculcar un "sistema común de categorías de percepción y de apreciación capaz de fundar una visión unitaria del mundo social" (Bourdieu, 2001, p. 91).

\section{LAS ESCUELAS RURALES FRONTERIZAS Y EL PORTUGUÉS. CIVILIZAR Y NACIONALIZAR}


La escuela en la construcción de las fronteras culturales y lingüísticas en el Uruguay de fines del siglo XIX

Como se ha observado, Varela le otorgaba a la educación una función política (formar ciudadanos para la República) y una función identitaria (crear nacionales para la nación); ambas al servicio de la delimitación de las fronteras del Estado nacional uruguayo.

La formación de ciudadanos implicaba en primer lugar civilizar al ignorante, a quien se lo identificó con el medio rural, siguiendo la ecuación ilustrada civilizaciónciudad / barbarie-campo. Esto explica el privilegio adjudicado a la campaña en la reforma educativa de 1877. Como el propio Varela (2012 [1879]) señalaba, su "punto de mira principal ha sido la campaña" (p. 238). Y argumentaba:

Hasta ahora, (...) las autoridades escolares se han fijado principalmente cuando se ha tratado de difundir la enseñanza pública, en los grandes centros de población y principalmente en ese gran centro que constituye la ciudad de Montevideo. Pero poco, casi ningún esfuerzo se ha hecho para variar las condiciones intelectuales y morales de los habitantes de los distritos rurales de nuestra campaña.

Allí las escuelas públicas no han ido nunca a tratar de difundir entre los habitantes, de lo que puede llamarse el desierto, el benéfico rayo de la educación, que los salve del abismo de la ignorancia [y los civilice].

Es tal vez como resultado inevitable de esa ignorancia de la campaña, que no ha sido posible establecer hasta ahora en nuestro país el funcionamiento regular de las instituciones republicanas, porque la República exige como condición indispensable la educación de los ciudadanos, y la democracia exige como condición indispensable para el juego armónico de todas las instituciones, la conciencia de sus actos en cada uno de los miembros que componen la sociedad.

Partiendo de esa base, nos hemos ocupado principalmente del establecimiento de escuelas rurales en campaña (Varela, 2012 [1879], pp. 238 y 239).

De este modo, la escuela podría cumplir su misión 'civilizadora'; esto es, transformaría al "ignorante" en "ciudadano", haciendo posible que cada individuo "tenga conocimiento de sus deberes y los ejercite con conciencia y honradez" (op. cit., p. 241). Revista Páginas de Educación. Vol. 9, Núm. 1 (2016) ISSN: 1688-5287; e-ISSN: 1688-7468 
La escuela en la construcción de las fronteras culturales y lingüísticas en el Uruguay de fines del siglo XIX

Efectivamente, todas las escuelas creadas (51 en 1877 y 57 en 1878; Varela, 2012 [1879]) se ubicaron en el interior del país, en el medio rural, y no en Montevideo, aunque la mayoría de la población residía en la capital. En octubre de 1877 había 208 escuelas, 63 en Montevideo y 145 en el resto del país. En octubre de 1878 había 259: seguían siendo 63 en Montevideo, pero en el resto del país pasó a haber 196 escuelas. Todas las escuelas creadas se ubicaron además no en las ciudades o pueblos cabeza de departamento (en donde incluso se eliminaron escuelas) sino en los distritos rurales $^{10}$. Esta política respondía al objetivo de aumentar el número de la población que recibía educación: según los datos estadísticos que Varela ofrece en su memoria escolar, en 1878 no recibían educación 70.000 niños de todo el país (de un total de 106.255), que significaban el $25 \%$ de los niños montevideanos y más del $80 \%$ de los niños del resto de los departamentos. Con la creación de las escuelas rurales aumentó en casi 3.000 la cantidad de niños que en el interior del país recibían educación (en Montevideo la cifra no cambió) (Varela, 2012 [1879]).

Dentro de las escuelas rurales, las fronterizas recibieron especial atención, debido a que la enseñanza en ( $\mathrm{y}$ del) idioma nacional, y su difusión en las regiones fronterizas con Brasil, fueron vistas como las estrategias más eficaces para alcanzar la nacionalización (al mismo tiempo que la civilización) de los habitantes del territorio uruguayo.

Cuando Varela (2012 [1879]) explicó las decisiones presupuestales tomadas, argumentó la necesidad de crear escuelas rurales señalando que "Las escuelas rurales fijas, cuando la concentración de la población lo permita, volantes cuando lo impida lo diseminado de los pobladores, son (...) una necesidad imperiosamente reclamada 0

\footnotetext{
${ }^{10}$ En 1878 se crearon tres escuelas en Canelones (total de escuelas: 30, 19 urbanas y 11 rurales), seis en San José (total de escuelas: 14, siete urbanas y siete rurales), siete en Florida (total de escuelas: 12, cinco urbanas y siete rurales), seis en Durazno (total de escuelas: nueve, tres urbanas y seis rurales), tres en Minas (total de escuelas: 10, tres urbanas y siete rurales), una en Maldonado (total de escuelas: 18, 11 urbanas y siete rurales), cinco en Cerro Largo (total de escuelas: 11, siete urbanas y cuatro rurales), cinco en Tacuarembó (total de escuelas: 13, siete urbanas y seis rurales), ocho en Salto (total de escuelas: 22, 11 urbanas y 11 rurales), 12 en Paysandú (total de escuelas: 25, ocho urbanas y 17 rurales), una en Colonia (total de escuelas: 16, ocho urbanas y ocho rurales). En Soriano se eliminaron seis escuelas (total de escuelas: 16, ocho urbanas y ocho rurales) y en Montevideo no hubo cambios (total de escuelas: 63) (Varela, 2012 [1879]).
}

Revista Páginas de Educación. Vol. 9, Núm. 1 (2016) ISSN: 1688-5287; e-ISSN: 1688-7468 
La escuela en la construcción de las fronteras culturales y lingüísticas en el Uruguay de fines del siglo XIX

impuesta por las más evidentes y las más premiosas exigencias de nuestra época y de nuestro país" (p. 196) ${ }^{11}$.

Agregó que en los departamentos limítrofes con Brasil la fundación de escuelas "se hace aún más urgente y más necesaria", porque "en ellos, por causas múltiples, el idioma, las costumbres y los sentimientos nacionales, van perdiéndose día a día, siendo suplantados por el idioma, por las costumbres y por los sentimientos de nuestros vecinos que nos invaden pacífica pero constantemente" (p. 196).

Las escuelas rurales fronterizas funcionarían como barrera sanitaria (cultural, política y lingüística) para frenar el avance de las costumbres de Brasil, los sentimientos de amor a la patria brasileña y el idioma portugués:

Si a esa invasión pacífica no se opone como única valla posible la escuela que instruya al niño en el idioma nacional, que le cree costumbres en armonía con las de los demás hijos del país, y que despierte y robustezca en el corazón de las nuevas generaciones el generosísimo sentimiento del amor a la patria, si la escuela pública no contraría la difusión del idioma extraño, de costumbres y sentimientos que no son los nuestros, natural es suponer para un porvenir cercano resultados que deben causar fundada alarma (Varela, op. cit., p. 197).

La cuestión de las escuelas fronterizas también fue uno de los principales temas de discusión en las primeras Conferencias de Inspectores Departamentales de Educación Primaria (de 1878), todos relativos a las escuelas rurales como ya he señalado ${ }^{12}$. En la discusión de la tercera sesión sobre la "mejor manera de establecer, organizar y mantener las Escuelas Rurales" (Actas de las Conferencias de Inspectores Departamentales, en Varela, 2012 [1879], p. 215), los inspectores de los departamentos

\footnotetext{
${ }^{11}$ Las escuelas rurales también cumplirían con una función económica muy específica: capacitar al proletariado rural en las nuevas técnicas agrícolas y ganaderas, así como constituirse en el dispositivo moral que entre otras cosas garantizara el respeto a la propiedad privada luego del alambramiento de los campos (Delio, 2014).

${ }^{12}$ Se discutieron los siguientes temas: proyectos de modificaciones del programa de las escuelas comunes para las escuelas rurales (1aㅗ sesión), organización del tiempo en estas escuelas (2aㅗ sesión), mejor organización y mantenimiento de las escuelas rurales (3a sesión), propiedad de los edificios de las escuelas rurales de chacras (4a sesión), características de las escuelas rurales de las estancias (fijas o volantes) (5a sesión), principios que deben seguirse en la confección de horarios de las asignaturas (6aㅗ sesión), duración de los ejercicios escolares (7ạ sesión), disposiciones sobre textos escolares (8as sesión) (Varela, 2012 [1879]).

Revista Páginas de Educación. Vol. 9, Núm. 1 (2016) ISSN: 1688-5287; e-ISSN: 1688-7468
} 
La escuela en la construcción de las fronteras culturales y lingüísticas en el Uruguay de fines del siglo XIX

fronterizos de Salto y Tacuarembó plantearon la cuestión del portugués. El inspector de Salto, Germán Fassauer, recomendó duplicar el número de escuelas rurales de su departamento, que eran 11 (cfr. Varela, 2012 [1879]), "como medio de difundir el idioma patrio" (op. cit., p. 216). El de Tacuarembó, Valentín Astor, propuso prohibir "toda enseñanza que no se haga en la lengua nacional en las Escuelas Rurales, sean públicas o particulares" (op. cit., p. 217).

Ambas mociones, aprobadas por unanimidad en el congreso, aparecían más fundamentadas en los informes anuales que cada uno había elevado al Inspector Nacional (y que conocían el resto de los inspectores departamentales). El inspector de Salto señalaba en su informe que:

En la extensa zona situada entre los ríos del Arapey y Cuareim no se escucha casi otro idioma que el portugués; allí la indolencia de los padres o encargados de los niños, se manifiesta de un modo deplorable y permitiendo que ellos se críen en la más completa ignorancia. Pero cuando se inclinan los habitantes de ese distrito a dar educación a sus hijos, los mandan al Brasil para que conjuntamente con la instrucción se perfeccionen en el idioma portugués y olviden el idioma patrio. Millares de ciudadanos pierde anualmente la República por ese hecho deplorable y sólo multiplicando los establecimientos de educación en la indicada zona, se lograría poner un dique a esos avances del elemento Brasilero (Inspector del departamento de Salto, Informe anual al Inspector Nacional, en Academia Nacional de Letras, 1982, p. 22).

Este discurso da cuenta del estrecho vínculo que se establecía entre el castellano y la identidad oriental por un lado, y el castellano como medio de educación y civilización por otro; siempre en oposición al portugués. Se vuelve a insistir en la doble función del castellano en gran parte del territorio nacional: nacionalizar y civilizar. El idioma nacional era un referente fundamental de la identidad nacional; daba cuenta de 
La escuela en la construcción de las fronteras culturales y lingüísticas en el Uruguay de fines del siglo XIX

ella; y su a vez era el instrumento para civilizar a la población y construir al ciudadano uruguayo difundiendo los valores nacionales ${ }^{13}$.

En la misma línea, aunque haciendo mayor énfasis en el fuerte vínculo identitario existente entre la población de la zona y el portugués, en su informe anual al Inspector Nacional, el inspector de Tacuarembó explicaba:

La mayoría de los que en la campaña del Departamento aspiran a que sus hijos se eduquen, prefiere un maestro particular que desconozca por completo el castellano, pero que en cambio hable perfectamente el portugués. Este inconveniente, de tan perjudiciales resultados, está llamado a desaparecer a medida que se vaya dando cumplimiento a las resoluciones gubernamentales referentes a la prohibición de la enseñanza de idiomas extraños en las escuelas particulares de la República. Para generalizar el idioma castellano, yo no veo otro medio, al menos por ahora, que ir aumentando el número de escuelas, pero esto tampoco es factible sin contar previamente con edificios propios y adecuados en donde establecerlas. Casi siempre que he tenido precisión de fundar alguna escuela en pasajes céntricos y poblados, he tocado con el mismo inconveniente: el vecindario no puede o no quiere alquilar o ceder un rancho porque cree que la escuela nacional no satisface sus miras, por no estar regentada por un preceptor portugués o brasilero. (Academia Nacional de Letras, 1982, p 22)

Tanto la propuesta del inspector de Salto como la del inspector de Tacuarembó dan cuenta de la extensión del uso del portugués en el norte del país a la vez que de la tarea asignada a la institución escolar para su eliminación, partiendo siempre del principio nacionalista de que en la nación no puede haber más que una lengua y que esta, en nuestro país, era el castellano. Las observaciones realizadas por los inspectores también evidencian la resistencia al aprendizaje del "idioma nacional", manifestada en diversas formas: ausentismo en las escuelas públicas; enseñanza con maestros de habla portuguesa, envío de los hijos para cursar estudios en Brasil, falta de colaboración para ceder los locales con fines educativos por el Estado.

\footnotetext{
${ }^{13}$ Sobre la función de la escuela vareliana en estos procesos, en particular a través de los libros de lectura usados, cfr. Oroño (2013). Sobre la concepción de sujeto pedagógico, Puiggrós (1990) asociado al modelo de ciudadano representado en ellos, cfr. Puiggrós (1990) y Martinis (2006).

Revista Páginas de Educación. Vol. 9, Núm. 1 (2016) ISSN: 1688-5287; e-ISSN: 1688-7468
} 
La escuela en la construcción de las fronteras culturales y lingüísticas en el Uruguay de fines del siglo XIX

La dificultad de contar con locales escolares en el norte del país fue especialmente tratada en las conferencias de inspectores de 1878. En la discusión de la cuarta sesión acerca de la propiedad de los edificios escolares en las escuelas de las chacras $^{14}$, luego de analizar si debían ser propiedad del Estado o de particulares, según consta en las Actas de las Conferencias de Inspectores Departamentales, se aprobó por unanimidad que:

Las casas de las Escuelas de Chacras deberán ser de propiedad del Estado, construyéndose por la acción combinada de éste y del vecindario en esta forma: el Estado concurrirá con una cantidad igual a lo que, sea en numerario, sea en especie o en trabajo, ofrezcan los vecindarios. Exceptuándose los distritos de los departamentos de Tacuarembó, Salto, Cerro Largo, Maldonado y Paysandú donde, predominando en grande escala el idioma brasilero puedan negarse los vecindarios a concurrir a la construcción de la Escuela como medio de contrariar la difusión del idioma nacional, en cuyo caso la casa para Escuela podrá ser construida por la sola acción del Estado. Cuando no pueda obtenerse por otras causas el concurso del vecindario la escuela se establecerá en casa particular. (Varela, 2012 [1879], p. 223)

Otra vez se deja constancia, como lo había manifestado Varela con anterioridad, que gran parte de los habitantes del país hablaban portugués y se sentían partícipes no de la nación uruguaya sino de la nación brasileña, razón por la cual se esperaba que no estuvieran de acuerdo con que se enseñara e impusiera el castellano por sobre el portugués y en consecuencia no ayudaran a financiar la construcción de edificios escolares. El idioma nacional se oponía al idioma brasileño y por su intermedio la nación uruguaya a la nación brasileña. Se evidencia la función asignada a las escuelas

\footnotetext{
${ }^{14}$ Las escuelas rurales se clasificaban en "Escuelas Rurales de las Estancias" y "Escuelas Rurales de las Chacras", según se instalasen en estancias o chacras, que podían ser además "volantes" o "fijas", dependiendo de la cantidad de estudiantes. Para que una escuela se constituyera como fija, esto es, con edificio estable, debía contar con al menos la asistencia media de 20 niños. En caso contrario se instalaban escuelas volantes, periódicas y mixtas. En este caso el maestro se trasladaba en diligencia (con todo el material escolar necesario para sus clases) a las estancias y la escuela "volante" funcionaba en forma rotativa durante cuatro meses en cada estancia. Las escuelas volantes debían instalarse a una distancia no mayor de cuatro leguas de una escuela fija. La policía, por otra parte, debía custodiar al maestro y a la escuela volante (Varela, 2012 [1879]), lo que indica la precariedad de la situación y la falta de seguridad existente en la campaña.
}

Revista Páginas de Educación. Vol. 9, Núm. 1 (2016) ISSN: 1688-5287; e-ISSN: 1688-7468 
La escuela en la construcción de las fronteras culturales y lingüísticas en el Uruguay de fines del siglo XIX

rurales, y en particular a las fronterizas, en la delimitación de las fronteras políticas, identitarias y lingüísticas. El discurso lingüístico era funcional al logro de la delimitación política del país.

La extensión del portugués en la región fronteriza con Brasil también era una inquietud del gobierno central. En una nota de fecha 22 de octubre de 1878, el Ministro de Guerra, José Montero, advertía al gobierno sobre la situación lingüística de la frontera y la amenaza que ello significaba para la nacionalidad ${ }^{15}$ :

S.E. el señor Gobernador ha podido apreciar en su reciente viaje a nuestros departamentos fronterizos con el Brasil, que en las escuelas allí establecidas, con excepción de las Municipales, es el idioma portugués el único que se enseña (...). Siendo como es, el idioma uno de los más vigorosos medios de expresión de la idea de la soberanía no es justo ni patriótico que la lengua castellana que heredamos de nuestros padres, sea propuesta a ninguna otra en el territorio de la República. El hombre que crece bajo el imperio de la lengua extraña, menoscaba necesariamente los sentimientos del patriotismo y de la dignidad del ciudadano. (Araújo, 1898, p. 171)

Esta nota dio lugar a un decreto firmado por Latorre el 30 de octubre de 1878, que estableció que "En todas las escuelas o colegios de enseñanza elemental, superior o científica [privados], se dará preferencia al idioma castellano, sin que esto importe excluir el estudio de los demás" (art. 1) (Araújo, op. cit., p.173).

La reglamentación y puesta en práctica de esta disposición estuvo a cargo precisamente de Varela (en tanto Inspector Nacional de Instrucción Pública), quien la estimaba "acertada, conveniente y justa" (Varela, 2012 [1879], p. 125), en la medida en que, como se vio, consideraba que el conocimiento del idioma nacional era el principal instrumento de nacionalización de la población, lo que requería a su vez la extensión de la educación primaria a todo el territorio nacional y la enseñanza obligatoria del castellano en todas las escuelas, tanto públicas como privadas. La reglamentación del decreto, de fecha 11 de febrero de 1879, estableció que los encargados de verificar el cumplimiento de la disposición fueran los inspectores departamentales mediante la

\footnotetext{
${ }^{15}$ Sobre este punto ver por ejemplo Barrios (2013) y Oroño (2013).

Revista Páginas de Educación. Vol. 9, Núm. 1 (2016) ISSN: 1688-5287; e-ISSN: 1688-7468
} 
La escuela en la construcción de las fronteras culturales y lingüísticas en el Uruguay de fines del siglo XIX

visita a los centros educativos particulares (Varela, 2012 [1879]). La medida tomada muestra asimismo la necesidad del Estado de regular las instituciones privadas, además de las públicas, para lograr sus objetivos civilizatorios y nacionalizadores ${ }^{16}$.

Esta inquietud compartida por Latorre y por Varela, por otra parte, da cuenta no solamente de la presencia del portugués en buena parte del país (así como de otras lenguas habladas en el territorio nacional), sino de las dificultades que existían para garantizar la enseñanza del castellano (y no solo en castellano) en las escuelas, por falta de recursos humanos que manejaran esta lengua en las escuelas. En 1877 casi la mitad de los maestros eran extranjeros: 196 maestros de un total de $396^{17}$. Diez años más tarde, sin embargo, ya empiezan a observarse los resultados de la política educativa nacionalizadora en la elección de maestros, y el desarrollo de la carrera magisterial en el país impulsadas por Varela: el $25 \%$ de los maestros de las escuelas públicas eran extranjeros ${ }^{18}$.

Al respecto, Varela expresaba: "Nos hemos preocupado seriamente de hacer que, en el personal enseñante, aumentara el número de los hijos del país. Son tan obvias las consideraciones que aconsejan un proceder semejante, que creo inútil exponerlas" (2012 [1879], p. 155). Explicaba que los docentes uruguayos, a diferencia

\footnotetext{
${ }^{16}$ A propósito, en su memoria, Varela señala que la medida fue muy criticada, en particular en las escuelas católicas, y que esto se debió no tanto a la oposición a que se enseñase el "idioma nacional", sino a que se conocieran los contenidos educativos enseñados en esas instituciones: "Sólo en un caso puede temerse la inspección: cuando las condiciones de la escuela o de la enseñanza sean tales que no puedan conservarse sino en el misterio. Es digno de notarse por otra parte, el que las censuras y los ataques que se han formulado contra la ley sobre enseñanza del idioma nacional y su reglamentación han partido, no como podría suponerse, de las escuelas donde sólo se enseñan idiomas extranjeros, que en adelante se verán obligadas a tomar, por lo menos, un maestro de idioma nacional, sino de los establecimientos sostenidos por comunidades religiosas o afiliados al elemento clerical. La resistencia es, pues, no a la enseñanza del idioma nacional, sino a la visita del Inspector. ¿’Por qué? Una de dos: o bien porque se teme que la visita del Inspector ponga a descubierto hechos que sólo pueden producirse impunemente en el misterio; o porque se abriga la pretensión de que los establecimientos clericales estén fuera del derecho común" (Varela, 2012 [1879], p. 125 y 126). Otra vez volvía a enfrentarse Varela al catolicismo.

${ }^{17} 130$ eran españoles, 19 argentinos, 14 franceses, 20 italianos, cuatro alemanes, tres brasileños, tres suizos, dos ingleses y un belga (Varela, 2012 [1879]).

${ }^{18}$ Había 380 escuelas públicas en todo el país en las que trabajaban 694 maestros, 175 de los cuales eran extranjeros (99 españoles, 25 argentinos, 14 franceses, 26 italianos y 11 de otros países) (Dirección General de Instrucción Primaria, 1889, p. 6).
}

Revista Páginas de Educación. Vol. 9, Núm. 1 (2016) ISSN: 1688-5287; e-ISSN: 1688-7468 
La escuela en la construcción de las fronteras culturales y lingüísticas en el Uruguay de fines del siglo XIX

de los extranjeros, se esforzarán especialmente "para despertar activamente en sus alumnos un amor verdadero y legítimo por la patria común" (op. cit., p. 156).

Coincidiendo con la preocupación de las autoridades escolares y gubernamentales por la situación lingüística de la frontera, en 1896 la Comisión de Instrucción Primaria del departamento de Rivera ${ }^{19}$, en una nota enviada a la Dirección General de Instrucción Pública, solicitaba que se tomaran medidas al respecto: "En ningún departamento, como en éste, predomina más el elemento brasilero y, fuera del centro de esta Villa, puede decirse que el idioma de esa nacionalidad es el corriente entre sus habitantes: hombres y niños orientales, descendientes de padres y abuelos orientales, no conocen otro; ni es cosa que llame la atención encontrarse con documentos oficiales, de autoridades subalternas, en el mismo idioma" (Dirección General de Instrucción Primaria, 1896, p. 50).

La observación se acompañaba con cifras censales de la "Población de la Villa de Rivera y su ejido", mostrando que efectivamente en esta región había menos uruguayos (2.534) que brasileños (2.586). También se señalaba la presencia de 369 extranjeros de otras nacionalidades (op. cit., p. 50) y se agregaba que "Con la población y el idioma, las costumbres brasileras predominan en gran parte del departamento" (op. cit., p. 52).

Esta situación sociolingüística se representó en términos negativos, estableciéndose también una correlación entre lengua-costumbres e ideas; se consideraba que "por sentimiento de nacionalidad, por espíritu de propia conservación" (op. cit., p. 50), era necesario controlar la frontera y "poner una valla a esa influencia y esa absorción que con el idioma y las costumbres pasa a las ideas y puede ser más, es una causa de perturbación" (op. cit., p. 50). La solución para lo que se consideraba un problema debía ser la educación escolar en general y la enseñanza del castellano en particular: "La Escuela es el primer remedio que ocurre al pensamiento: la educación de la juventud; que los niños de hoy, los ciudadanos de mañana, aprendan el idioma

\footnotetext{
${ }^{19}$ Este departamento se creó en 1884 con la ley $n^{\circ} 1.757$ del 1 de octubre de ese año. El 18 de setiembre del mismo año se había creado el de Artigas (ley $n^{\circ} 1.754$ ).

Revista Páginas de Educación. Vol. 9, Núm. 1 (2016) ISSN: 1688-5287; e-ISSN: 1688-7468
} 
La escuela en la construcción de las fronteras culturales y lingüísticas en el Uruguay de fines del siglo XIX

patrio, y con él se les inculquen las ideas y sentimientos de la nacionalidad oriental" (op. cit., p. 52). La Comisión solicitó entonces a las autoridades escolares nacionales la creación de más escuelas estatales en la región, para agregar a las 19 ya existentes.

Las "escuelas fronterizas" se valoraron especialmente en función de los objetivos buscados, incluyendo el idioma. En un discurso pronunciado en 1896 en el marco de los festejos en Artigas por el aniversario de la Jura de la Constitución, el Inspector de Escuelas del departamento de Artigas, Pedro Stagnero, expresaba que estas escuelas tenían la "misión" de "nacionalizar" la población de frontera, imponiendo el castellano ("nuestro idioma") y las costumbres hispanas de la capital ("nuestras costumbres"). Nótese en la cita, la oposición entre un nosotros "claro y luminoso", de "robustos pulmones", a un ellos "anémico" y "errante":

La escuela, señores, la escuela oriental, tiene una misión sagrada que cumplir. Educar, instruir, moralizar la juventud, no es la misión exclusiva de las escuelas fronterizas. Necesitamos nacionalizar, necesitamos imponer nuestro idioma, nuestras costumbres, los atributos todos de una patria grande, tanto más grande, señores, cuanto más claros y luminosos se destacan los limbos de nuestra historia. Necesitamos redimir, salvar para la patria a veinte mil ciudadanos que viven la vida anémica de las tribus errantes, sin que el aire que respiran les lleve una sola molécula del oxígeno vital del patriotismo que anima los robustos pulmones de nuestra gran capital. (op. cit., p. 67$)^{20}$

Estos documentos, fechados casi veinte años después de iniciada la reforma escolar vareliana, muestran el alcance de una tensión que se instaló definitivamente: la

\footnotetext{
${ }^{20}$ En 1906, la preocupación subsistía: de los cinco temas a discutir en el Cuarto Congreso de Inspectores, uno refería a uso del portugués en las escuelas estatales en detrimento del idioma nacional ("Programa de las escuelas fronterizas") y el otro a las formas de erradicarlo ("Medios de encaminar las escuelas fronterizas a la mayor difusión del idioma patrio"). Las actas de las sesiones de este congreso (Dirección General de Instrucción Pública, 1907) muestran las discrepancias de opinión entre los Inspectores Departamentales sobre la presencia del portugués en las regiones de frontera: el portugués como problema; la disminución de asignaturas en las escuelas de frontera a favor de la enseñanza del "idioma patrio", historia nacional y Constitución de la República; la necesidad de crear más escuelas en esta zona; el lugar de los maestros en la nacionalización de las regiones fronterizas; el uso del portugués en las aulas por alumnos y maestros; la utilidad de que los maestros hablaran y escribieran portugués. Revista Páginas de Educación. Vol. 9, Núm. 1 (2016) ISSN: 1688-5287; e-ISSN: 1688-7468
} 
La escuela en la construcción de las fronteras culturales y lingüísticas en el Uruguay de fines del siglo XIX

persistencia de la educación escolar estatal en erradicar el portugués y el empeño de la población en continuar hablándolo ${ }^{21}$.

\section{CONCLUSIONES}

En el último cuarto del siglo XIX, la principal preocupación de la élite uruguaya era establecer las fronteras políticas, económicas y culturales del país. Para ello había que nacionalizar y civilizar a la población (en especial a la población rural) a través de, entre otras cosas, la enseñanza del castellano, el idioma nacional. En este contexto, el portugués fue representado como especialmente problemático, por sus implicancias económicas, políticas y culturales: los lusohablantes estaban en una región que incluía la frontera norte del país, esas tierras estaban en manos de brasileños, y sus habitantes respondían a tradiciones y costumbres lusitanas más que hispanas (Behares, 1984; Elizaincín et al., 1987; Barrios et al., 1993; Barrios, 2013).

La escuela, obligatoria y en castellano, y en particular las escuelas rurales fronterizas, fueron vistas como la principal herramienta para alcanzar un Estado homogéneo en cuanto a lengua y cultura. Para lograrlo, y a partir del reconocimiento de la extensión del portugués en gran parte del país, se desarrolló una planificación educativa y lingüística muy cuidada para revertir la situación. Para su concreción se aunaron los esfuerzos del gobierno y del Inspector Nacional de Instrucción Pública, José Pedro Varela, y fueron esenciales los inspectores departamentales que, encargados de llevar las disposiciones educativas a cada una de las escuelas de su jurisdicción y de controlar su puesta en práctica por parte de los maestros, funcionaron como enlace entre éstos y la administración central.

Como otros hombres de su generación, Varela se adjudicó un papel social muy particular, una función política destacada, como él mismo señalaba en el Banquete de la Juventud de 1872 que congregó a la élite juvenil montevideana:

\footnotetext{
${ }^{21}$ Sobre la representación de la situación sociolingüística de la frontera norte del Uruguay en este período y en otros posteriores, cfr. Barrios (2008, 2013 y 2015).

Revista Páginas de Educación. Vol. 9, Núm. 1 (2016) ISSN: 1688-5287; e-ISSN: 1688-7468
} 
La escuela en la construcción de las fronteras culturales y lingüísticas en el Uruguay de fines del siglo XIX

Los jóvenes de hoy son los hombres de mañana; el porvenir entero les pertenece. [i]Les pertenecerá también la culpa si el pueblo continúa como hasta ahora en el embrutecimiento de la ignorancia, en la pobreza del atraso, en el dolor intenso de la guerra civil! Suya será la gloria si arranca a los viejos partidos su tradicional rencor, a los malos gobiernos su tradicional injusticia, al pueblo flagelado su tradicional extravío, y a los ciudadanos todos de la patria su tradicional intolerancia. Suya será la gloria si llega pronto el día en que los hijos de la República Oriental, puedan repetir con verdadera y legítima satisfacción las grandes palabras de Beaumarchais: soy ciudadano (Varela, 1872, pp. 86 y 87).

Pero en su caso no sólo diseñó un modelo cultural (en torno a valores nacionales y modernos) destinado "a la conformación de ideologías públicas" (Rama, 1998, p. 36; especificidad que el autor le atribuye a las élites culturales), sino que lo hizo efectivo liderando la reforma escolar iniciada en 1877.

Los Estados nacionales necesitan crear una conciencia nacional mediante la homogeneización de los ciudadanos y el desarrollo de una cultura nacional que organice el espacio público al compartir formas de pensar y de actuar (Hobsbawm, 1992; Anderson, 1993). La escuela vareliana se ocupó de esta tarea al colocar al castellano no solo como expresión idiosincrática del espíritu nacional (Fishman, 1989; Haugen, 2001), sino como medio de difusión de las ideas nacionales y como organizador del aparato burocrático del Estado (Anderson, 1993; Hobsbawm, 1992; Gellner, 1988), poniendo en primer plano la función demarcativa (Fishman, 1989; Zimmerman, 2008) del "idioma nacional" en relación con el portugués como atributo de la nación uruguaya.

La política lingüística estudiada (y las representaciones que la justificaron así como las que formuló e hizo circular) tuvo enormes consecuencias en el mapa sociolingüístico del país. La instrucción escolar pública en castellano junto con la prohibición de hablar portugués en las escuelas y la difusión de representaciones negativas sobre esta lengua lograron que en cuarenta años cambiara la realidad 
La escuela en la construcción de las fronteras culturales y lingüísticas en el Uruguay de fines del siglo XIX

lingüística del norte de Uruguay: dieron lugar a una comunidad bilingüe-diglósica ${ }^{22}$, con el castellano como variedad alta, prestigiosa, y el portugués como variedad baja, reprimida y desvalorizada.

\section{REFERENCIAS}

Academia Nacional de Letras (1982). Estudio sobre el problema idiomático fronterizo. Montevideo: Academia Nacional de Letras.

Altamirano, C. (2008). Introducción general. En C. Altamirano (dir.), Historia de los intelectuales en América Latina. Volumen I: La ciudad letrada, de la conquista al modernismo (pp. 9-28). Madrid: Katz.

Anderson, B. (1993). Comunidades imaginadas. Reflexiones sobre el origen y la difusión del nacionalismo. Buenos Aires: Fondo de Cultura Económica.

Araújo, O. (1898). Legislación escolar cronológica. Tomos II-IV (años 1877-1897). Montevideo: Dornaleche y Reyes.

Araújo, O. (1911). Historia de la escuela uruguaya. Montevideo: El siglo ilustrado.

Ardao, A. (1971). Las Obras Pedagógicas de Varela. En C. Ardao, Etapas de la inteligencia uruguaya (pp. 113-136). Montevideo: Udelar.

Argone, C. (1987). La Ley de Educación Común. Análisis y Juicio Crítico. Montevideo, ANEP- CEP.

Barrán, J. P. (2008). Historia de la sensibilidad en el Uruguay. Montevideo: Banda Oriental.

Barrios, G. (2008). Discursos hegemónicos y representaciones lingüísticas sobre lenguas en contacto y de contacto: español, portugués y portuñol fronterizos. En D. Da Hora y R. Marques de Lucena (orgs.), Política Lingüística na América Latina (pp. 79-103). Joăo Pessoa: Idéia- Editora Universitária.

Barrios, G. (2013). Language diversity and national unity in the history of Uruguay. J.

\footnotetext{
${ }^{22}$ Sobre la situación diglósica fronteriza y su evolución, cfr. Behares (1984 y 2007).

Revista Páginas de Educación. Vol. 9, Núm. 1 (2016) ISSN: 1688-5287; e-ISSN: 1688-7468
} 
La escuela en la construcción de las fronteras culturales y lingüísticas en el Uruguay de fines del siglo XIX

Del Valle (ed.), A Political History of Spanish: The Making of a Language (pp. 197-211). Nueva York: Cambridge University Press.

Barrios, G. (2015) Política lingüística y dictadura militar en Uruguay (1973-1985): los informes institucionales sobre la situación lingüística fronteriza. Estudios de Lingüística del Español, 36, 527-557.

Barrios, G., Behares, L., Elizaincín, A., Gabbiani, B., y Mazzolini, S. (1993). Planificación y políticas lingüísticas en Uruguay. Iztapalapa, 29, 177-190.

Barth, F. (1976). Los grupos étnicos y sus fronteras. La organización social de las diferencias culturales. México: Fondo de Cultura Económica.

Behares, L. (1984). Planificación lingüística y educación en la frontera uruguaya con Brasil. Montevideo: Instituto Interamericano del Niño.

Behares, L. (2007) Portugués del Uruguay y educación fronteriza. En C. Brovetto, N. Brian y J. Geymonat (eds.), Portugués del Uruguay y educación bilingüe (pp. 99171). Montevideo: ANEP.

Behares, L. y Brovetto, C. (2009). Referencias al lenguaje en las leyes de educación de Uruguay. Actas del IV Encontro Internacional de Pesquisadores de Políticas Lingüísticas (pp. 95-102). Santa María: UFSM-AUGM.

Bourdieu, P. (2001). ¿Qué significa hablar? Economía de los intercambios lingüísticos. Madrid: Akal.

Bralich, J. (1989). José Pedro Varela. Sociedad burguesa y reforma educacional. Montevideo: Ediciones del Nuevo Mundo.

Caetano, G. (1992). Identidad nacional e imaginario colectivo en Uruguay. La síntesis perdurable del Centenario. En H. Achugar y G. Caetano (comps.), Identidad uruguaya: ¿mito, crisis o afirmación? (pp. 75-96). Montevideo: Trilce.

Caetano, G. y Rilla, J. (1994). Historia contemporánea del Uruguay. De la Colonia al Mercosur. Montevideo: CLAEH - Fin de Siglo.

Coll, M. (2009). Bilingüismo sem diglosia: O português e o espanhol no norte do Uruguai no século XIX. En A. M. Carvalho (org.), Português em Contato (pp. 237- 256). Madrid: Iberoamericana Vervuert.

Revista Páginas de Educación. Vol. 9, Núm. 1 (2016) ISSN: 1688-5287; e-ISSN: 1688-7468 
La escuela en la construcción de las fronteras culturales y lingüísticas en el Uruguay de fines del siglo XIX

Delio, L. (2014). Consideraciones económicas determinantes en las políticas educativas rurales uruguayas (1877-1918). Revista de la Facultad de Derecho, 37, 111-145.

Dirección General de Instrucción Primaria. (1889). Boletín de Enseñanza Primaria. Tomo I.

Dirección General de Instrucción Primaria. (1896). Boletín de Enseñanza Primaria. Tomo XV.

Dirección General de Instrucción Pública. (1907). Anales de Instrucción Primaria. Tomo IV.

Elizaincín, A. (1979). Estado actual de los estudios sobre el fronterizo uruguayobrasileño. Cuadernos del Sur, 12, 119-140.

Elizaincín, A., L. Behares y G. Barrios (1987). Nos falemo brasilero. Dialectos portugueses en Uruguay. Montevideo: Amesur.

Fairclough, N. (2001). Discurso e mudança social. Brasilia: Editoria Universidade de Brasilia.

Fishman, J. (1989). Language and ethnicity in minority sociolingüistic perspective. Clevelon-Philadelphia: Multilingual Matters.

Gellner, E. (1988). Naciones y nacionalismos. Madrid: Alianza.

Haugen, E. (2001). Dialeto, língua, nação. Em M. Bagno (org.), Norma lingüística (pp. 97- 114). San Pablo: Loyola.

Hobsbawm, E. (1992). Naciones y nacionalismo desde 1780. Barcelona: Crítica.

Jodelet, D. (1993). La representación social: fenómenos, concepto y teoría. En S. Moscovici (ed.), Psicología social (pp. 469-494). Barcelona: Paidós.

Martinis, P. (2006). Sobre escuelas y salidas: la educación como posibilidad, más allá del contexto. En P. Martinis (comp.), Pensar la escuela más allá del contexto (pp. 259- 279). Montevideo: Psico Libros.

Moscovici, S. (ed.). (1993). Psicología social. Barcelona: Paidós.

Mena Segarra, E. y Palomeque, A. (2011). Historia de la educación uruguaya. Tomos I y II. Montevideo: Ediciones de la Plaza.

Nahum, B. (1994). Manual de historia del Uruguay. Montevideo: Banda Oriental.

Revista Páginas de Educación. Vol. 9, Núm. 1 (2016) ISSN: 1688-5287; e-ISSN: 1688-7468 
La escuela en la construcción de las fronteras culturales y lingüísticas en el Uruguay de fines del siglo XIX

Oroño, M. (2011). La escuela pública uruguaya y el idioma nacional en dos períodos históricos: fines del siglo XIX y mediados del siglo XX. Letras, 42, 217- 247.

Oroño, M. (2013). Las representaciones sociolingüísticas en textos escolares de la educación primaria uruguaya: las series de libros de lectura de Vásquez Acevedo, Figueira y Abadie-Zarrilli. [Tesis de Maestría inédita]. Facultad de Humanidades y Ciencias de la Educación, Universidad de la República.

Palomeque, A. (2012). Prólogo. Em A. Palomeque (comp.), José Pedro Varela y su tiempo. Escritos de José Pedro Varela y documentos de época. Tomo1. (pp. 1353). Montevideo: ANEP.

Puiggrós, A. (1990). Sujetos, disciplina y currículum en los orígenes del sistema educativo argentino. Buenos Aires: Galerna.

Rama, Á. (1998). La ciudad letrada. Montevideo: Arca.

Sociedad de Amigos de la Educación Popular. (1869). La Educación Popular: 1-5. Montevideo: Imprenta del Telégrafo Marítimo.

Varela, J. P. (1872). El banquete de la juventud. Colección de los discursos pronunciados en el Banquete que tuvo lugar en la noche del 13 de abril de 1872. Montevideo: Imprenta a vapor de La Paz.

Varela, J. P. (1910 [1874]). La educación del pueblo. Montevideo: El Siglo llustrado.

Varela, J. P. (1964 [1876]). La legislación escolar. Montevideo: Ministerio de Instrucción Pública y Previsión Social.

Varela, J. P. (2012 [1879]). Memoria del Inspector Nacional. 1877-1878. En A. Palomeque (comp.), José Pedro Varela y su tiempo. Escritos de José Pedro Varela y documentos de época. Vol.6 (pp. 89- 252). Montevideo: ANEP.

Vidart, D. y Pi, R. (1969). El legado de los inmigrantes. Montevideo: Nuestra Tierra.

Zimmermann, K. (2008). Políticas lingüísticas e identidad: una visión constructivista. En U. Mühlschlegel y K. Süselbeck (eds.), Lengua, nación e identidad: la regulación del plurilingüismo en España y América Latina (pp. 21- 40). Madrid: Iberoamericana: Madrid.

Revista Páginas de Educación. Vol. 9, Núm. 1 (2016) ISSN: 1688-5287; e-ISSN: 1688-7468 